\title{
An epidemiological study of oral contraceptives and breast cancer
}

\author{
M P VESSEY, RICHARD DOLL, KEENA JONES, KLIM McPHERSON, D YEATES
}

British Medical fournal, 1979, 1, 1755-1758

\section{Summary and conclusions}

During 1968-77, 707 women aged 16-50 years with newly diagnosed breast cancer and 707 matched controls were interviewed at eight teaching hospitals in London and Oxford about their use of oral contraceptives. Eighty-six of the patients with breast cancer were matched with controls with gall-bladder disease; these subjects were omitted from the main analyses, which thus related to 621 case-control pairs.

The results were reassuring. A few statistically significant differences in oral contraceptive use were found between the breast cancer and control groups, but the data were subdivided in many ways, so that some "significant" differences would have been expected to occur by chance. The only subgroup in which the evidence for a positive association between pill use and breast cancer was at all convincing comprised women aged 46-50 years, but trends in those aged 41-45 were by and large in the opposite direction and results of combined analysis gave no cause for concern.

Information on clinical stage was available for 487 patients with breast cancer treated before the end of 1975. Those who had never used oral contraceptives had appreciably more advanced tumours at presentation than those who had been using the pill during the year before detection of the lump, while past users of the pill occupied an intermediate position. This difference in staging was reflected in the pattern of survival. Oral contraceptives may have had a beneficial effect on tumour growth and spread, though diagnostic bias could not be definitely excluded.

\section{Introduction}

In December 1968 we began a controlled study of the use of oral contraceptives by women admitted to hospital for primary treatment of cancer of the breast. Preliminary findings from the first 90 cases were published in $1972,{ }^{1}$ and three years later we reported on an additional 232 affected women. ${ }^{2}$ The results provided no indication of a relation, either positive or negative, between oral contraceptives and breast cancer. We now summarise our findings from a total of 707 patients with cancer of the breast admitted to hospital up to the end of August 1977.

\footnotetext{
University Department of Social and Community Medicine, Oxford OX1 3QN

M P VESSEY, MD, FFCM, professor of social and community medicine KLIM MCPHERSON, MA, PHD, university lecturer in medical statistics

D YEATES, MSC, PHD, research officer

Department of the Regius Professor of Medicine, Radcliffe Infirmary, Oxford OX2 6HE

SIR RICHARD DOLL, DM, FRS, regius professor of medicine Imperial Cancer Research Fund, London WC2A 3PX KEENA JONES, MA, research interviewer
}

\section{Subjects and methods \\ METHODS}

The methods used in the early phases of the study have been described. ${ }^{12}$ In brief, up to the end of 1971 married women aged 16-39 years being treated for newly diagnosed breast cancer at University College, the Royal Free, the Middlesex, Charing Cross, and Guy's hospitals, London, were interviewed by a trained medical social worker or nurse about their medical, obstetric, menstrual, contraceptive, and social histories. For each patient two married controls were selected from women inpatients in the same hospital who had certain acute medical or surgical conditions or had been admitted for routine elective operations that were deemed unlikely to be associated with the use or lack of use of any contraceptive. The controls matched the women with breast cancer with respect to age (within five years) and parity (nil, one or two, or three or more term births) and were interviewed in the same way.

From January 1972 the procedure was modified: the age range of the patients with cancer was increased to $16-45$ years; only one control was selected in each case; matching for age was arranged within five-year age groups (16-20, 21-25, and so on); and a sixth hospital (Mount Vernon, Middlesex) agreed to participate. Further extension of the study followed in mid-1974: the age range was increased to 16-50 years, and women admitted to the Radcliffe Infirmary and Churchill Hospital, Oxford, were included.

Throughout the study the case notes of each patient with breast cancer have been reviewed (usually by MV), the diagnosis confirmed, the treatment recorded, and clinical information abstracted to enable the tumour to be staged according to the TNM system. ${ }^{3}$ So far as possible this procedure has been carried out in the absence of information about the contraceptive practices of the patient concerned. Each patient with breast cancer has also been followed up yearly to see whether she is still alive.

In the present report the overall results are first presented as simple contingency tables that take no account of the matched design of the study. In subsequent analyses relative risks are estimated, allowance is made for confounding variables, and interactions are sought, the "adapted" linear logistic procedure described by Breslow et $a^{4}$ being used. This method preserves the matching and entails fitting models for specified sets of variables thought to influence the risk of the disease. For simplicity one of the pair of controls matched with each of the 90 patients with breast cancer interviewed before the end of 1971 was deleted at random before analysis (although any control with gall-bladder disease was invariably the one deleted; see below). Matching of cases and controls is thus one-to-one throughout.

\section{SUBJECTS}

From 1 December 1968 to 31 August 1977, 707 women receiving primary treatment for breast cancer were interviewed. Table Im (miniprint) lists the diagnoses in the 707 matched controls; 86 of these had gall-bladder disease. Since cholelithiasis is now well established as an adverse effect of oral contraceptives ${ }^{5-7}$ we decided to omit these 86 controls and corresponding breast cancer cases from our main analyses, which thus relate to 621 case-control pairs.

Of the 621 women with breast cancer, 133 were aged 16-35 years, 168 36-40 years, $20541-45$ years, and $11546-50$ years. The relatively small proportions of patients in the two oldest age groups reflect the gradual increase in upper age limit for entry to the study. Eighty-eight of the patients were nulliparous, 327 had had one or two term births, and 206 had had three or more term births.

\section{Results}

The analyses were carried out separately on data collected within each of the three phases of the study (December 1968 to December 
1971 ; January 1972 to June 1974 ; July 1974 to August 1977 ) as well as for all the data combined. There was no evidence of heterogeneity in the results between the different phases, so we present here only the overall findings.

\section{USE OF ORAL CONTRACEPTIVES}

As in our previous analyses, the reference point used to assess the contraceptive histories of the women with breast cancer was taken as the time when the patient first became aware of a lump (or other abnormality) in her breast, with corresponding times for the matched controls.

Table IIm shows the proportion of patients in each group who had been using the pill during the month before the lump was first detected (or during the corresponding month for the matched controls) together with the proportion who had used oral contraceptives only before that time. Table IIIm shows the interval between the time the pill was first used and the time the lump was detected, and table IVm the total duration of oral contraceptive use. Table $\mathrm{Vm}$ gives the types of oral contraceptives used; products containing chlormadinone acetate or megestrol acetate are listed separately, since these progestogens have been implicated as a cause of breast tumours in beagles. ${ }^{8}$ In all four tables the data on the two groups of women are remarkably similar.

\section{OTHER METHODS OF CONTRACEPTION}

Table VIm summarises the use of other reversible methods of contraception reported by the women in the two groups. There was no suggestion that the patients with breast cancer had any less need of contraception than the controls; indeed, the converse was true, 105 $(16.9 \%)$ of the controls saying that they had never used any method of contraception compared with $62\left(10.0^{\circ}\right)$ of the patients with cancer. This difference between the cases and controls was apparent in all age and parity subgroups.

\section{COMPARABILITY OF GROUPS}

The controls were selected for their comparability to the patients with breast cancer with respect to age, parity, marital state, and date and hospital of admission. They were also found to be comparable with regard to religion, country of origin, and whether pregnant or in the puerperium. Table VIIm lists the characteristics that differed

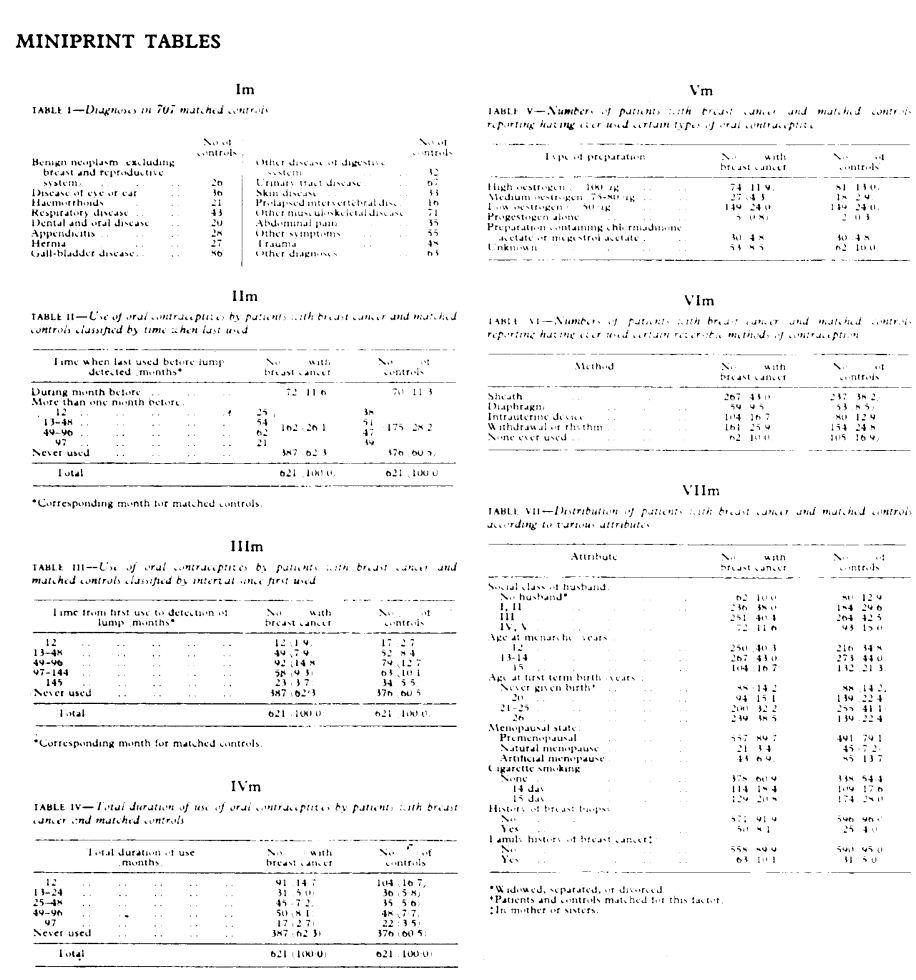

between the two groups-namely, social class, age at menarche, age at first term birth, menopausal state, smoking habits, history of breast biopsy, and family history of breast cancer. All the differences (save for smoking habits) were consistent with the known epidemiology of breast cancer. ${ }^{9}$

\section{MULTIVARIATE ANALYSIS}

In our first series of analyses using the method of Breslow et al ${ }^{4}$ four main measures of exposure to oral contraceptives were considered: use at any time; interval since last use (never, up to 12 months, 13-48 months, 49 months or more); interval since first use (never, up to 48 months, $49-96$ months, 97 months or more); and total duration of use (never, up to 12 months, 13-48 months, 49 months or more). All the attributes listed in table VIIm were incorporated in the model as possible confounding variables, although, as expected from earlier work, ${ }^{12}$ they had little effect on the estimation of relative risks. Separate analyses were made within four age groups (16-35, $36-40,41-45,46-50)$ and three parity groups $(0,1-2, \geqslant 3)$ as well as for all the data combined. Table VIII summarises the results obtained overall and in the different age groups. Only three statistically

TABLE VIII-Risk of breast cancer in relation to different measures of exposure to oral contraceptives by age.* In each analysis, risk among women never using oral contraceptives is taken as unity ( $95 \%$ confidence limits given in parentheses)

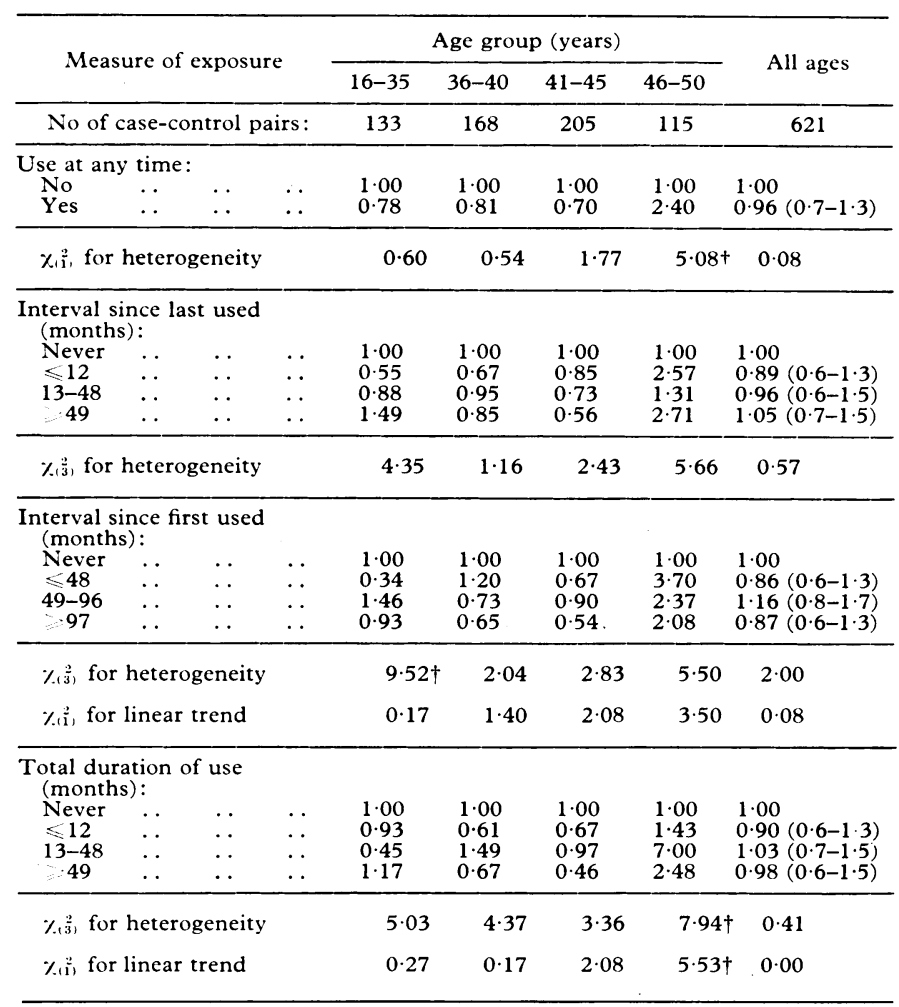

*Risks adjusted for effects of social class, age at menarche, age at first term birth menopausal state, smoking habits, history of breast biopsy, and family history of breast cancer.
$+\mathrm{P}<0.05$.

significant values of $y^{2}$ for heterogeneity were found out of 20 examined. Of these, two concerned women aged 46-50; however, trends in relative risks for the 41-45-year and 46-50-year age groups were by and large in opposite directions, and combined analysis of these two age groups provided no suggestion of any association between oral contraceptives and breast cancer. Similarly, analysis within the parity groups showed no statistically significant differences.

In a second series of analyses we examined different types of oral contraceptives. Again separate analyses were made within age and parity groups as well as overall. Only two significant differences were detected: an increased risk associated with preparations containing medium amounts of oestrogen $(75-80 \mathrm{~kg})$ in women aged $36-40$ years (relative risk $2.26 ; \mathrm{P}<0.05$ ), and a decreased risk associated with preparations of unknown type in women aged 41-45 (relative risk $0.34 ; \mathrm{P}<0.05)$ 
A third series of analyses searched for any specific effect of oral contraceptive use before the first term birth and for interactions between exposure to the preparations and late age at first term birth, a history of breast biopsy, and a family history of breast cancer. Table IXm gives the basic data (subdivided by total duration of use), which provide little indication of any effect; this was confirmed by the multivariate analyses, which showed no significant associations. The numbers of subjects included in most of the analyses, however, were small.

In a final analysis we examined the proportions of women in the two groups who reported that they had never used any reversible method of contraception (see table VIm). The difference, which was highly significant $(P<0.001)$, was not explicable in terms of any confounding variable.

\section{DISCARDED CASES}

To test whether the results had been modified by excluding the 86 patients with breast cancer who had been matched with controls suffering from diseases of the gall bladder we rematched as many as possible with controls included in the main analysis. Eighty-four case-control pairs were successfully rematched in this way for age, parity, and year of interview. The findings were closely similar to those of the main analysis-for example, percentages of patients with cancer and matched controls never using oral contraceptives: $58 \cdot 3 \%$ and $66.7 \%$; percentages with total duration of use exceeding 48 months: $10 \cdot 7 \%$ and $7 \cdot 1 \%$.

\section{DIAGNOSTIC BIAS}

Since there has long been anxiety about the possible relation between oral contraceptives and breast cancer, we thought that both women using the pill and their medical attendants might be especially alert for the appearance of breast lumps, which might lead to serious diagnostic bias. The data in table $\mathrm{X}$, however, show no evidence of a relation between pill use and the delay before seeking treatment for breast cancer or the reported frequency of regular self-examination of the breasts. Nevertheless, there was strong evidence that women using oral contraceptives had their breasts routinely examined more often by a medical attendant than other women. Despite this some 95\% of breast cancers in both users and non-users of the pill were detected by the woman herself or by her husband.

TABLE X-Diagnostic bias. Data relate to 329 case-control pairs interviewed after fune 1974 (some relevant questions not asked before then)

\begin{tabular}{|c|c|c|c|c|}
\hline \multirow{2}{*}{\multicolumn{2}{|c|}{. }} & \multicolumn{3}{|c|}{ Use of oral contraceptives* } \\
\hline & & $\begin{array}{l}\text { Never } \\
\text { used }\end{array}$ & $\begin{array}{c}\text { Used } \\
\text { only in } \\
\text { past }\end{array}$ & $\begin{array}{l}\text { Used } \\
\text { recently }\end{array}$ \\
\hline \multicolumn{2}{|c|}{$\begin{array}{l}\text { o of patients with over three months' delay between } \\
\text { detection of lump and start of treatment }\end{array}$} & $25 \cdot 8$ & $29 \cdot 3$ & $22 \cdot 4$ \\
\hline \multicolumn{2}{|c|}{$\%$ of patients in whom medical attendant found lump } & $4 \cdot 1$ & $8 \cdot 5$ & $4 \cdot 1$ \\
\hline \multirow{2}{*}{$\begin{array}{l}\text { of patients with breast cancer and } \\
\text { matched controls reporting regular } \\
\text { self-examination of breasts }\end{array}$} & $\int$ Patients & $31 \cdot 3$ & $38 \cdot 8$ & $32 \cdot 9$ \\
\hline & Controls & $37 \cdot 2$ & 32.5 & $34 \cdot 6$ \\
\hline \multirow{2}{*}{$\begin{array}{l}\% \text { of patients with breast cancer and } \\
\text { matched controls reporting regular } \\
\text { breast examination by medical attendant }\end{array}$} & Patients & $18 \cdot 1$ & $20 \cdot 7$ & $30 \cdot 6$ \\
\hline & Controls & 13.4 & 18.5 & $44 \cdot 2$ \\
\hline
\end{tabular}

*"Used recently" indicates use during year before detection of lump (or corresponding time in controls); "Used only in past" indicates use only before that time.

\section{MINIPRINT TABLES}

IXm

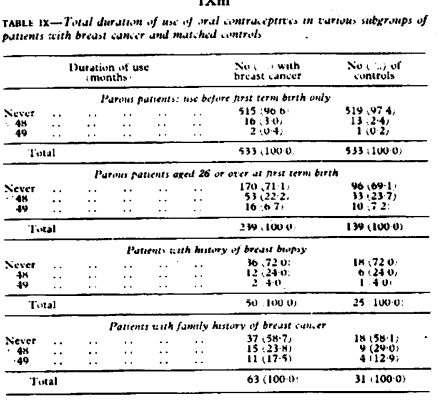

\section{CLINICAL STAGE OF BREAST TUMOURS}

Table XI gives the clinical stage classification of the 487 patients with breast cancer treated before the end of 1975 . Women who had never used oral contraceptives had appreciably more advanced tumours than those who had been using the pill during the year before detection of the lump, while past users of the pill occupied an intermediate position. This association could not be explained in terms of any potentially confounding variables such as the age of the patient or the hospital providing treatment.

We undertook a detailed examination of the individual features taken into account in clinical staging of breast tumours (size, skin changes, nipple retraction, fixation to pectoral muscle and chest wall, palpability and mobility of lymph nodes, distant metastases) but were unable to identify any particular characteristic or characteristics that distinguished cancers occurring in women using the pill from those occurring in women not doing so.

\section{MORTALITY OF PATIENTS WITH BREAST TUMOURS}

All but five of the 487 patients with breast cancer included in table XI were followed up until the end of December 1976. There were 113 deaths. Table XIIm gives an analysis of mortality (log-rank method ${ }^{10}$ ) in relation to oral contraceptive use. Women who had been using oral contraceptives during the year before their tumour was detected had a lower mortality than past users of the pill, while these women had a lower mortality than those who had never used oral contraceptives. These differences, however, were no longer statistically significant after allowance had been made for the effect on survival of clinical stage.

TABLE XI-Stage classification of 487 patients with breast cancer (TNM system) treated before 31 December 1975. Figures are numbers of patients (percentages in parentheses)

\begin{tabular}{lccc}
\hline \multirow{2}{*}{ Clinical stage } & \multicolumn{3}{c}{ Use of oral contraceptives* } \\
\cline { 2 - 4 } & $\begin{array}{c}\text { Never } \\
\text { used }\end{array}$ & $\begin{array}{c}\text { Used only } \\
\text { in past }\end{array}$ & $\begin{array}{c}\text { Used } \\
\text { recently }\end{array}$ \\
\hline I $\left(\mathrm{T}_{1-2}\right.$ No Mo) & $168(54 \cdot 2)$ & $61(62 \cdot 2)$ & $60(75 \cdot 9)$ \\
II ( $\left.\mathrm{T}_{1-2} \mathrm{~N}_{1} \mathrm{Mo}\right)$ & $70(22 \cdot 6)$ & $22(22 \cdot 4)$ & $10(12 \cdot)$ \\
III or IV (other TNM categories) & $72(23 \cdot 2)$ & $15(15 \cdot 3)$ & $9(11 \cdot 4)$ \\
\hline Total & $310(100 \cdot 0)$ & $98(100 \cdot 0)$ & $79(100 \cdot 0)$ \\
\hline
\end{tabular}

*"Used recently" and "Used only in past" defined in table $X$. $\chi_{\left(\frac{2}{4}\right)}=13.97 ; P<0.01$.

\section{Discussion}

Many case-control studies of the relation between oral contraceptives and breast cancer are in progress (especially in the United States) but the results of relatively few have been published. ${ }^{51-16}$ Limited information is available from three cohort studies, but the numbers of new cases of disease are small. ${ }^{6}{ }^{71}$ Thomas $^{18}$ and Vessey ${ }^{19}$ concluded that the available data provide little cause for alarm. It is necessary, however, to add some qualifying remarks about the case-control study (including 452 women with breast cancer) conducted by Fasal and Paffenbarger ${ }^{13}$ in the San Francisco Bay area. These workers found no significant overall differences in oral contraceptive use between the patients with cancer and the controls. They did, however, find an excess of women with cancer who had used oral contraceptives for two to four years (but not of women using the preparations for shorter or longer periods) and also noted an apparent increase in the risk of breast cancer among women who had used oral contraceptives for six years or more and had, in addition, previously had a biopsy for benign breast disease. They later reported that use of oral contraceptives before the first pregnancy was also associated with an increased risk. ${ }^{20}$ Brinton et al, ${ }^{16}$ who analysed data obtained during the Breast Cancer Detection Demonstration Project in the United States, found some indication that oral contraceptives might interact unfavourably with the established risk factors for the disease. The associations were, however, based on small numbers and did not for the most part reach statistical significance. 
Our findings are reassuring. A few statistically significant differences in oral contraceptive use were found between the breast cancer and control groups, but the data were subdivided in many ways, so that some "significant" differences would have been expected to occur by chance alone. There was, perhaps, some evidence of an association between pill use and breast cancer in women aged 46-50 years, but in view of the contrasting findings in women aged 41-45 this may well have been one of the chance results.

We were unable to test adequately the suggestions of Fasal and Paffenbarger and Brinton et al, that the use of oral contraceptives before the first term birth or in the presence of risk factors for breast cancer may be harmful, because of the small numbers of relevant observations. Nevertheless, our data, so far as they go, offer no support to their findings.

The finding that a smaller proportion of women with breast cancer than matched controls had never used any method of contraception has not to our knowledge been reported before. If confirmed this observation could be important; one possible explanation, for example, might be that infertile women, who had less need for contraception, were less likely to develop breast cancer. It might also be argued that the risks of breast cancer associated with oral contraception should be estimated only from data relating to those patients and controls reporting the use of some birth-control method. On this basis our study suggests that the relative risk of breast cancer among those with any use of oral contraceptives is only about $0 \cdot 80$.

The negative association between cigarette smoking and breast cancer was unexpected but of only borderline significance $(P \approx 0.03)$; it largely disappeared after adjustment for social class and age at first term birth. We none the less decided to retain cigarette smoking as a possible confounding variable in the multivariate analyses.

Our search for evidence of diagnostic bias had largely negative results. Although women using oral contraceptives reported that their breasts were routinely examined by a medical attendant much more often than other women, some $95 \%$ of cancers in users and non-users alike were discovered by the woman or by her husband. This finding argues against diagnostic bias as the explanation for the negative association between the clinical stage of the tumour and oral contraceptive use and raises the possibility of a beneficial biological effect of contraceptive steroids on tumour growth and spread. We cannot, however, be sure that our questions about breast self-examination were sensitive enough to detect small but important differences in behaviour between the contraceptive groups. For example, pill users may be generally more aware of changes in their breasts than non-users during washing, dressing, and so on without specifically engaging in more frequent "self-examination."

In our study oral contraceptive users who developed breast cancer had a better prognosis than non-users, though most of the difference was attributable to the association between pill use and clinical stage of the tumour. Spencer et $a l,{ }^{21}$ in a study at Guy's Hospital of 44 patients with breast cancer who had taken contraceptive steroids during the year before diagnosis and 44 who had not, also found that those who had taken oral contraceptives had a better prognosis; the difference, however, was confined to the rate of recurrence in those with pathological stage II tumours. Since some Guy's Hospital patients were included in our study we reanalysed our data leaving them out. The results were essentially the same as those given in tables XI and XIIm. In our view the possibility that the pill has a beneficial biological effect on the rate of growth of breast cancer, though not proved, should not be ignored.

Although our results are reassuring, we must emphasise that relatively few of the women who were interviewed had had prolonged exposure to contraceptive steroids and that information about any interaction between the pill and other risk factors is limited. It should also be remembered that over the years women have tended to adopt the pill at progressively younger ages and to use oral contraceptives to delay the first birth as well as to space or limit later births. Data derived from women who, like those in the present study, mostly started to use the pill in their 20 s or later may not be applicable to girls first starting to use the pill in their mid-teens.

We thank the medical staff at the participating hospitals for allowing us to study patients under their care, and Mrs Moya Simmonds, Mrs Judith Young, Mrs Kate Rodriguez, and Miss Ruth Harris for help in conducting the interviews and following up the patients. We are also grateful to the Medical Research Council and the Imperial Cancer Research Fund for financial support.

\section{References}

${ }^{1}$ Vessey, M P, Doll, R, and Sutton, P M, British Medical fournal, 1972, 3, 719.

2 Vessey, M P, Doll, R, and Jones, K, Lancet, 1975, 1, 941.

3 International Union against Cancer, TNM Classification of Malignant Tumours. Geneva, UICC, 1968.

4 Breslow, N E, et al, American fournal of Epidemiology, 1978, 108, 299.

5 Boston Collaborative Drug Surveillance Program, Lancet, 1973, 1, 1399.

${ }^{6}$ Royal College of General Practitioners, Oral Contraceptives and Health. London, Pitman Medical, 1974.

? Vessey, M P, et al, Fournal of Biosocial Science, 1976, 8, 373.

${ }^{8}$ British Medical fournal, 1975, 4, 608.

9 MacMahon, B, Cole, P, and Brown, J, Fournal of the National Cancer Institute, 1973, 50, 21.

10 Peto, R, et al, British fournal of Cancer, 1977, 35, 1.

11 Arthes, F G, Sartwell, P E, and Lewison, E F, Cancer, 1971, 28, 1391.

12 Henderson, B E, et al, fournal of the National Cancer Institute, 1974, 53, 609.

${ }^{13}$ Fasal, E, and Paffenbarger, R S, fournal of the National Cancer Institute, $1975,55,767$.

14 Sartwell, P E, Arthes, F G, and Tonascia, J A, fournal of the National Cancer Institute, $1977, \mathbf{5 9}, 1589$.

15 Kelsey, J L, et al, American fournal of Epidemiology, 1978, 107, 236.

${ }_{16}$ Brinton, L A, et al, fournal of the National Cancer Institute, 1979, 62, 37.

17 Ory, H, et al, New England fournal of Medicine, 1976, 294, 419.

18 Thomas, D B, Cancer Research, 1978, 38, 3991.

19 Vessey, M P, British fournal of Family Planning, 1979, 4, 65

${ }^{20}$ Paffenbarger, R S, et al, Cancer, 1977, 39, 1887.

21 Spencer, J D, Millis, R R, and Hayward, J L, British Medical Fournal, $1978,1,1024$

(Accepted 16 May 1979)

ONE HUNDRED YEARS AGO On the 13th of October last, I was called to see Master —_ (one of a family of four children), whom I found suffering from a diphtheritic patch on the left tonsil, accompanied by the usual prostration of strength, a temperature of $103 \mathrm{deg}$, and a pulse of 130 . I had here a case of diphtheria in a household of ten persons. Isolation, as far as possible, was at once enjoined, and the treatment which I have with unvarying success pursued for many years was adopted; the main features of which are: the application of sulphurous acid to the throat, nitro-hydrochloric acid internally, and as large a quantity of nourishment as possible, given assiduously day and night, with alcoholic stimulants according to circumstances. One nurse and the three remaining children were received into the house of friends in a heighbouring village, whose courage and humanity deserve to be recorded; but, on October 20th, one of these children developed diphtheria and was brought back to his home. The under-nursemaid, who had remained in the infected house, fell ill on the same day, and there the spread of the disease ended.

In the first case, which was also the most severe, the maternal instincts were too strong to be influenced by my protests; notwithstanding which, the mother, a delicate lady, nursed the child throughout his illness (with occasional assistance), without showing a symptom of the disease, an immunity she shared with the others in attendance. Now, the point I desire to make specially prominent is, that all those attending on the cases were considered for the time being as also affected, and treated with sulphurous acid gargle, etc, accordingly. To this prophylactic treatment I attribute their immunity from attack, as the specific fungoid growth found on the throats of the diphtheritic must necessarily be nipped in the bud by the action of the acid, so destructive to this form of life. I dare say I may not be alone in the adoption of this course, but never having seen it recommended, I have thought it but right to give others the benefit of my experience in the matter. (British Medical fournal, 1879.) 